\title{
Malignant Germ cell Tumor of Ovary: An Unusual Combination and An Irony of Fate
}

\author{
Arpita Sutradhar ${ }^{1 *}$, Enam Murshed Khan ${ }^{1}$, Shaikat Gupta ${ }^{2}$, Sudipta Kr Maitra² and Somdeep Ghosh ${ }^{2}$ \\ 'Pathology, Apollo Gleneagles Hospital \\ ${ }^{2}$ Surgical Oncology, Apollo Gleneagles Hospital
}

\begin{abstract}
Malignant mixed ovarian germ cell tumors are very rare malignant ovarian germ cell tumors, with a very high degree of malignancy. They are aggressive cancers affecting young adolescent girls. The commonest combination reported in literature is dysgerminoma and endodermal sinus tumors. Fertility sparing surgery followed by combination chemotherapy is the treatment of choice. The objectives of this case report are the advanced age of presentation, unusual histopathological combination, and the irony of infertility treatment. We report a rare case of 40-year-old woman with Malignant mixed germ cell tumor comprising of components of endodermal sinus tumor, immature teratoma, dysgerminoma and embryonal carcinoma. Patient was on hormonal therapy for the cause of infertility, presented with complains of lower abdominal pain, constipation and incomplete evacuation of bladder for 2 months. Transvaginal ultrasonography and CT scan showed a large multicystic space occupying lesion with predominant solid component in midline abdominopelvic location. Tumor markers i.e., AFP, Prolactin and CA125 were raised. Total abdominal hysterectomy and bilateral salpingoophorectomy, pelvic and retroperitoneal node resection, peritonectomy and omentectomy was performed.
\end{abstract}

Keywords: Malignant Mixed Germ Cell Tumor, Dysgerminoma, Endodermal Sinus Tumor, Fertility.

\section{Introduction}

Malignant ovarian germ cell tumours are rare but aggressive tumours in the female genital system and primarily affect adolescents and young adults. ${ }^{[1]}$ Germ cell tumours are a histologically heterogenous group of tumours that share a common origin: the primitive germ cell of the embryonic gonad. They constitute about 20-25 $\%$ of all ovarian neoplasms; However, only $5 \%$ of germ cell tumours are malignant, with most (95\%) being benign mature cystic teratomas ${ }^{[2]}$. The incidence ranges from 1 to $6 \%$ in the West and 8 to $19 \%$ in $\mathrm{Asia}^{[3]}$. The most common form of malignant germ cell tumours is dysgerminoma $(80 \%)$, endodermal sinus tumour $(70 \%)$, and immature teratoma (53\%) reported in a series ${ }^{[4]}$ Malignant mixed germ cell tumours are quite rare cancers, seen in $8 \%$ cases of germ cell tumors but are very aggressive in nature ${ }^{[5]}$. We report a 40-year-old adult female undergoing treatment for infertility with a very rare malignant mixed germ cell tumor of 4 components namely Endodermal sinus tumors(70\%), Immature Teratoma (15\%), dysgerminoma (10\%) and embryonal carcinoma (5\%).

\section{Case Summary}

A 40-year-old woman presented with chief complaints of lower abdominal pain, constipation and incomplete evacuation of bladder for 2 months. She was known hypertensive, diabetic and was on hormonal therapy for treatment of infertility. Routine hematological investigations showed haemoglobin $8.2 \mathrm{~g} / \mathrm{dl}$, total count $8600 /$ cumm and platelet count $432 \times 1000$. Routine biochemical tests were within normal range. Tumor markers levels were CA125:209.5U/ml, Carcinoembryonic Antigen: $2.7 \mathrm{ng} / \mathrm{ml}$, Beta Human chorionic gonadotrophin : $6 \mathrm{mIU} /$ $\mathrm{ml}$, Alpha fetoprotein: $655 \mathrm{ng} / \mathrm{ml}$, Lactate dehydrogenase: 336U/L and Serum Prolactin :30.3 ng/ml. Transvaginal sonography revealed a large multicystic SOL with predominant solid component in midline abdomino-pelvic location, small ascites confined to pelvis and a peritoneal nodule .Computed Tomography scan whole abdomen revealed(Figure 1) a large approx. 102x160x115 mm(AP $\mathrm{x}$ TR x CC) relatively well defined thick walled complex solid cystic lesion in pelvis with thick enhancing internal septations and solid enhancing peripheral components deriving its vascular supply from vascular pedicle of left adnexa .Bilateral ovaries could not be identified separate from the lesion. Suspicious retroperitoneal and external iliac lymph nodes identified. Intraoperatively a large left adnexal mass was identified which was excised and sent for frozen biopsy. On frozen, it was reported as highgrade malignant tumor. This was followed by total abdominal hysterectomy and Right Salpingoophorectomy, enbloc pelvic and involved field peritonectomy, appendectomy, low retroperitoneal and bilateral pelvic lymphadenectomy and supracolic omentectomy for staging of the tumour.

On gross examination (Figue2) tumor measured 20x11x6 $\mathrm{cm}$ and weighed $1211 \mathrm{gm}$. External surface was smooth, bosselated and partially ruptured capsule. Serial cut 
sections revealed solid and multiloculated cystic, variegated cut surface with hemorrhagic and necrotic areas. Microscopy showed a malignant mixed germ cell tumor of variable composition (Figure3). Predominant (70\%) component was that of yolk sac tumor showing reticular and microcystic areas with Schiller-Duval bodies. Second most prominent component was in form of immature cartilage and neuroectodermal elements (15\%). Third component was that of dysgerminoma (10\%). Fourth and least component was that of embryonal carcinoma $(5 \%)$. Capsule was ruptured without any surface involvement. Lymph nodes and omentum were free of tumour. However macroscopic peritoneal deposits were noted.

Patient was discharged in satisfactory condition. Adjuvant chemotherapy was planned to be started after postoperative recovery.

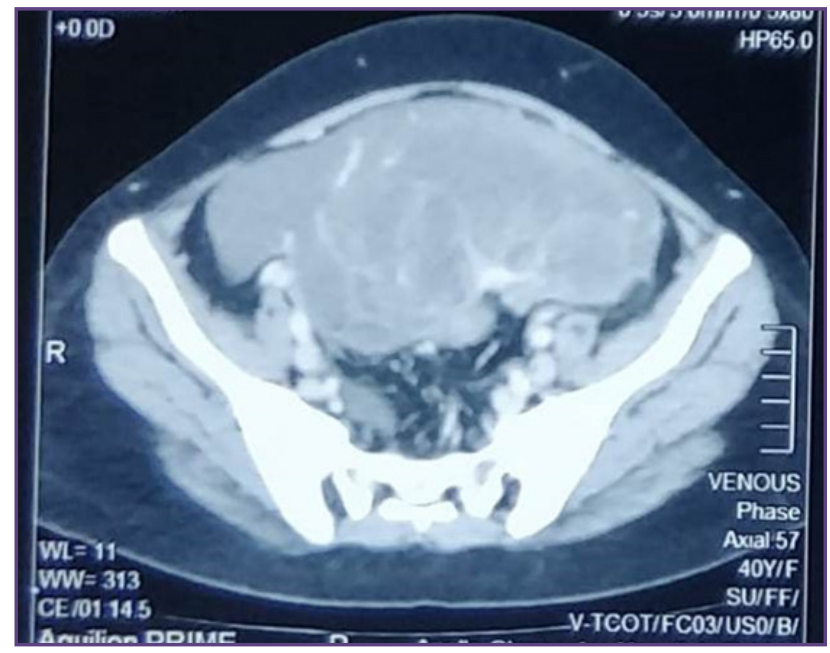

Fig. 1: CT scan of whole abdomen shows Large multicystic predominantly solid midline abdomino -pelvic mass.

\section{Discussion}

Rare combination of uncommon age of presentation, uncommon germ cell components and history of hormonal therapy for infertility makes the case unusual.

The average age of presentation of germ cell tumours is 13.8 years (4-27) ${ }^{[6]}$. Most of them are unmarried and premenarcheal. In the first two decades of life, more than $60 \%$ of ovarian tumours are of germ cell origin, and one third of these are malignant ${ }^{[7]}$.But our case was unique in presenting at the age of 40 years.

Most mixed germ cell tumours consist of two components. The commonest combination is dysgerminoma with endodermal sinus tumour accounting for one-third of cases. Other combinations include choriocarcinoma and immature teratoma in decreasing order of frequency. In a study conducted at Guru Gobind Singh Medical college and Hospital, Dept. of Obstetrics \& Gynecology, Faridkot, Punjab out of 528 cases of ovarian malignancy, they found five cases of malignant mixed germ cell tumour in which most common histological subtypes were of two components like endodermal sinus tumour and immature teratoma(n-3) followed by mature and immature teratoma (n-1),endodermal sinus tumour and embryonal carcinoma (n-1) ${ }^{[8]}$ Cases of mixed germ cell tumour of endodermal sinus tumour and embryonal carcinoma are rare and tumours with multiple (4 or more) components of endodermal sinus tumour $(70 \%)$, immature teratoma(15\%), dysgerminoma $(10 \%)$ and embryonal carcinoma $(5 \%)$ are exceptional.

Studies are there supporting the fact that several fertility drugs incite malignant ovarian surface epithelial tumours and sex cord stromal tumours. However not much evidence is there regarding the relation of fertility drugs and malignant ovarian germ cell tumours as in our case.

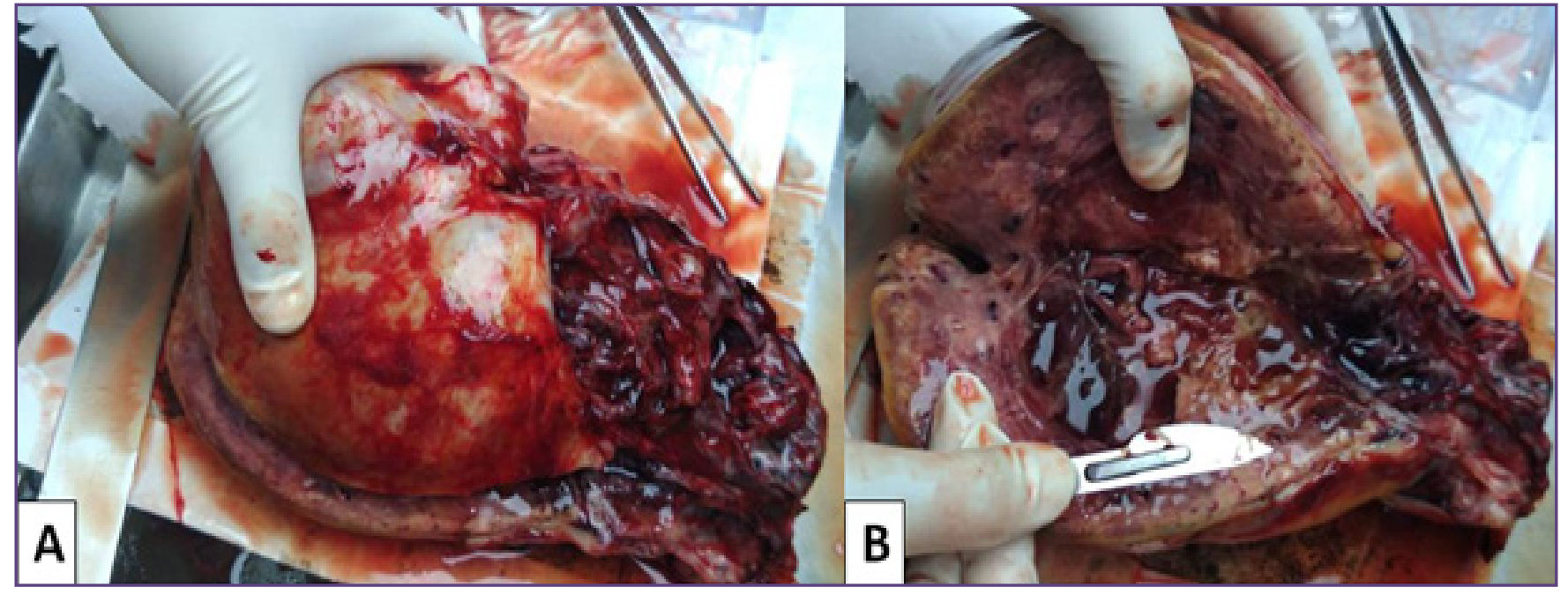

Fig. 2A: Gross picture showing ruptured capsule. 2B: Gross cut surface is multicystic, necrotic and hemorrhagic. 


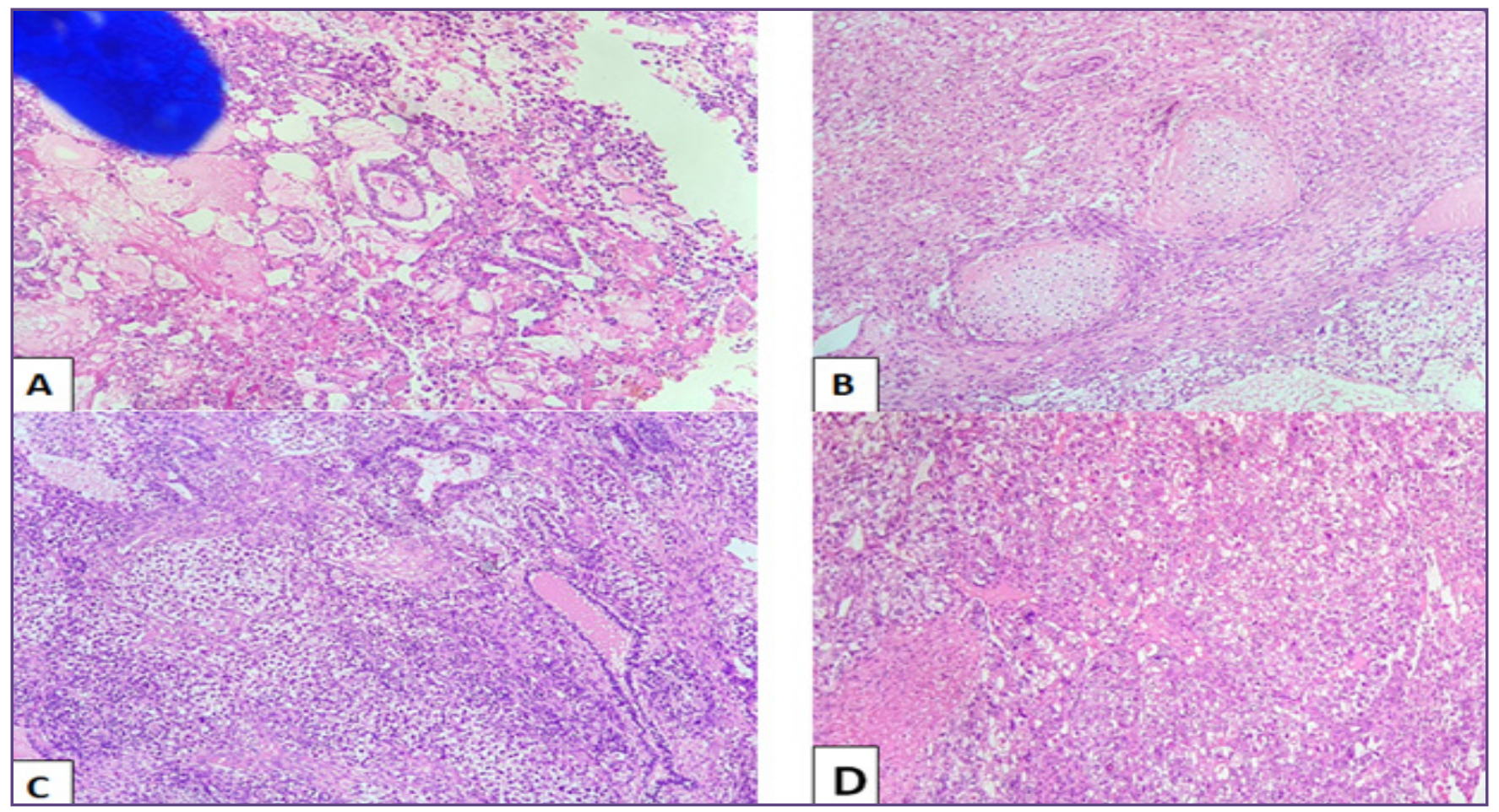

Fig. 3: H \& E, 10X Photomicrograph of the four components of Malignant mixed germ cell tumor of ovary: A) Schiller-Duval bodies, B) Immature cartilage, C) Immature neuroectodermal elements, D) Embryonal carcinoma.

Unilateral oophorectomy and surgical staging are the minimal surgery in ovarian germ cell tumour if conservation of fertility is of concern. In our case extensive debulking surgery was done taking into consideration the extensive spread and advanced age of patient.

\section{Conclusion}

The present case puts on record an adult female with a rare combination of four germ cell components in a malignant mixed germ cell tumour of ovary and the need for extensive sampling for microscopic study, since each component adds to ultimate prognosis.

\section{References}

1. Brown J, Friedlander M, Backes FJ, et al. Gyanecologic Cancer Inter-group (GCIG) consensus review for ovarian germ cell tumors. Int J Gynaecol Cancer .2014;242014;24(9 Suppl 3):S48-S54.

2. Talerman A. Germ cell tumors of the ovary. In: Kurman RJ, ed. Blaustein's pathology of the female genital tract.5th ed. New York, NY: Springer ,2002;1391.
3. Lim FK, Chanrachakul B, Chomg SM, Ratnma SS: Malignant ovarian germ cell tumors: experience in National University Hospital of Singapore. Ann Acad Med Singapore 1998,27(5):657-661.

4. Gershenson DM, Del Junco G, copelan LJ, Ruthledge FN: Mixed germ cell tumors of ovary. Obstet Gynaecol 1984,64(2):200-206.

5. Munemane a, Munemame M. Malignant mixed germ cell tumors of the ovary-a report of 2 cases.int J Med Sci Public Health .2014;3(1):105-7.

6. Brammer HM 3rd, Buck JL, Hayes WS, Sheth S, Tassavoli FA: From the archives of AFIP. Malignant germ cell tumors of the ovary: radiologic-pathologic correlation. Radiographics 1990,10:715-724.

7. Norris HJ, Jensen RD. Relative frequency of ovarian neoplasms in children and adolscents. Cancer 1972;30(3):713-719.

8. Lajya DG, Balpreet K, Rama KB. Malignant Mixed Germ cell tumors of the Ovary: A series of Rare cases: Original Article .J Reprod Infertil. 2019;20(4):231-236.

\section{*Corresponding author:}

Dr. Arpita Sutradhar, 58 Canal circular Road, Apollo Gleneagles Hospital, Kolkata-700054

Phone: +918420701100

Email: s.arpita3@gmail.com

\author{
Date of Submission $\quad: 12 / 06 / 2021$ \\ Date of Final Revision : 08/08/2021 \\ Date of Acceptance $\quad: \quad 18 / 08 / 2021$ \\ Date of Publication $\quad: 30 / 08 / 2021$
}

